\title{
The Characteristics of English and Chinese language and the Readability of Translation
}

\author{
Zhuosheng Yang \\ College of Foreign Languages, Neijiang Normal University, Neijiang Sichuan, 641199, China
}

Keywords: Readability, Dynamic, Stative, Nominalization, Hypotaxis, Parataxis

\begin{abstract}
Based on the contrastive analysis of the major differences between the two languages in aspects like dynamic \& stative description, hypotaxis in English \&parataxis in Chinese, active \& passive sentences et al, an effort is made to explore how to achieve readability in the process of translating the two languages.
\end{abstract}

\section{Overview}

English and Chinese are different language systems rooted in entirely varied cultural backgrounds and formed two expression habits and thinking patterns of different styles, which will inevitably bring many troubles in interlingual conversion. Translators with different cultural backgrounds usually feel at sea for English-Chinese translation conversion. Although some common stiff and obscure words in translation don't influence understanding but readers may feel like a fishbone getting stuck in the throat. It is because such translation destroys the sense of natural beauty in the language. With the influence and constraint of the source language, the target language becomes a nondescript language; actually, it is the problem of readability.

What is readability? It specifically refers to the intelligibility and smoothness or naturalness of the target language for readers. Mr. Mao Dun put forward two standards for translation: loyalty and smoothness. Thus, it can be seen that readers mainly refers to the latter. Next, how to improve the readability of target language is mainly explored by comparing several major differences between English and Chinese.

\section{Linguistic features and translation of English and Chinese}

\section{Dynamic vs. Stative}

Without inflection in Chinese verbs, apart from serving as the predicate, Chinese verbs and verb phrases can also be used as the subject, object, attribute, adverbial modifier and complement etc. For instance, “说说不要紧(Saying doesn’t matter!)”; “学好外语很重要(It is very important to learn a foreign language well.);” “他特别注重调查研究(He paid particular attention to investigations)”; “学 习计划/参考资料(learning plan/references);” “注意看/留心听 (watch carefully/listen out)”; “孩子 们激动得跳了起来 (The kids jumped up excitedly.)”. Thus, the large number of verbs used in Chinese result in the significantly dynamic characteristics of Chinese. However, English verbs can only serve as the predicate. If used as other sentence components, only the noun, adjective, adverb or non-predicate forms can be used, so the frequency of using verbs in English is much lower than that in Chinese and the outstanding nominalization leads to the typical stative characteristics of English. In short, the dynamic characteristics of Chinese are shown in the large number of verbs used while the stative characteristics of English are shown in the heavy use of nouns, adjectives, propositions, prepositional phrases and adverbs etc.

Chinese verbs vs. English nominalization

In A Grammar of Contemporary English, R. Quirk et al said: "Broadly speaking, nouns can be characterized naturally as "stative" in that they refer to entities that are regarded as stable * At the opposite pole, verbs can be equally naturally characterized as "dynamic". It means that words can be divided into the dynamic ones and stative ones. Nouns are stative and verbs are dynamic. 
As previously mentioned, without inflection, Chinese verbs almost can serve as all component of a sentence; but Chinese verbs can only serve as the predicate and must be converted into nouns or non-predicate forms when serving as other components. Therefore, verbs are frequently used in Chinese, which thus has outstanding dynamic characteristics. On the contrary, due to the low use frequency of verbs in English, many verbs in Chinese are habitually converted into other forms in English; especially, verbs are usually converted into nouns and this is called "nominalization" in English. Such tendency is rather popular in English so the use frequency of nouns in English is much higher than that in Chinese. There may be inflection or not inflection in nominalization. It means that other types of words can be directly flexibly used as nouns. Many nouns in English are converted from other types of words plus noun affixes. The high popularity and high use frequency of nominalization can be seen from the countless noun affixes in English. Mass use of nouns results in the obvious stative characteristics of English. For example:

My denial of his accusations impressed the jury.

There is a demand for an end to taxation on entertainment.

Students often ignore such difference in translation and do the translation according to the structure of English, so the target language does not conform to the original meaning or fails to agree with the expression habit in Chinese. For instance:

1) He is a bad singer.

A. 他是一个坏的歌唱家。

B. 他歌唱得不好。

It can be seen that A is obviously wrong and fails to agree with the habit of Chinese expression; but B is more smooth and readable. It is because “歌唱家 (singer)”, a stative noun, is used in A and the verb “唱 (sing)” is used in B; the practical effects are greatly different. Let's try to compare the following two sentences:

2) A list of all the discoveries by accident would fill a long book.

A. 所有偶然发现的单子可以填满一大本书。

B. 要是将所有偶然发现都一一罗列出来的话, 怕是得写满厚厚一本书。

Chinese verbs vs. English adjectives

Adjectives are another type of words with typical stative characteristics. In English, the weak verbs such as "be" and "become" plus adjectives are usually used so English is remarkably stative. However, when they are translated into Chinese, people habitually translated them into verbs because it is difficult to use adjectives or other types of words to express them; otherwise, the smoothness of Chinese target language cannot be realized. For instance:

3) They are aware of the importance of education.

他们明白教育的重要性。

4) It was in the early September, when the trees in each family courtyard were heavy with apples or pears.

九月初, 家家户户院子里的苹果和梨树都挂满果实。

If Chinese students translate the above-mentioned Chinese into English, most of them will use verbs and the sentence translated may be largely different from the original English sentence. In reality, English speakers probably prefer to use adjectives rather than verbs to express the same meaning. If we are aware of this in translation from Chinese to English, our target language will show more characteristics of English and thus our English sentences will looks more English; and vice versa.

Chinese verbs vs. English prepositional phrases

It is believed that all English learners are familiar with prepositional phrases, which are another characteristic of English. Almost each adjective, noun and verb has their own prepositional collocations. The use of a large number of prepositional phrases also intensifies the stative characteristics of English. Prepositional phrases are often used with the assistance of weak verbs. For instance:

5) The examination is in progress. 考试正在进行中。 
6) The house was on fire. 房子着火了。

Verbs are used in both of the Chinese example sentences above. It is difficult to imagine the result without the use of verbs.

It is also needed to point out that prepositions must be used together with objectives. Most objectives in English are nouns so the stative characteristic of English is further strengthened. When translating Chinese to English, one must consciously cultivate the habit of using prepositional phrases and try to show such characteristics of English so as to translate Chinese to smooth English. For instance:

7) The delight of the children at the sight of some dish on the table showed it was a rarity.

孩子们一看见桌上的某道菜便兴高采烈，可见这是他们平时难得吃到的东西。

The four prepositions connected with five nouns in the subject of the sentence above visually reveal the stative tendency of English by using prepositions and nouns. On the contrary, the translation with verbs in Chinese is unavoidable; otherwise, the smoothness of translation cannot be realized. If we translate the Chinese to English again, how many people can give such a brief and fluent sentence like the original English sentence and meanwhile show the basic styles and characteristics of English.

\section{Hypotaxis vs. parataxis}

Hypotaxis is important in English so the integrity and prudence of the structure of sentence are emphasized; parataxis is important in Chinese, which is dispersing in the form but concentrated in the meaning. Please compare the Chinese sentence and English sentence translated below:

归途见林柿正黄, 就马上摘食之。士人呼止, 弗听, 嚼之, 涩甚, 急吐去。下骑受泉漱 口，始能言。土人大笑。盖柿须摘下，煮一沸始去涩，余不知也。

On my way back I saw some wild persimmons, which were of a ripe color. I picked one from a tree while on horseback, and was going to eat it then and there. The native people tried to stop me, but $\underline{I}$ wouldn't listen to them. Only after taking a bite did I find it to have a harsh flavor. So much so that $\underline{I}$ quickly spat it out and had to come down from horseback and rinse my mouth at a spring before

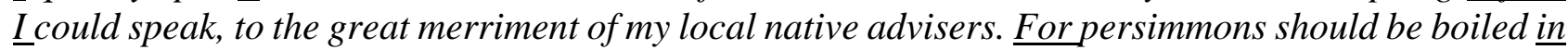
order to take away their harsh flavor, but I learnt it a little too late.

The examples above vividly reveal the parataxis in English and hypotaxis in English:

Through comparison, we can find that the underlined part added in the English translation helps to achieve the structural integrity and prudence as well as coherence and smoothness. Without the underlined part, the readability will be greatly reduced and the sentence will immediately become stiff, obscure and difficult to read. However, without such things, the seemingly dispersing Chinese sentences are refined, implicit, concise and comprehensive and still read smoothly. This is the so-called "concentrated meaning in dispersing forms". Next, we'll specifically study the underlined part to find out the "dispersing” form in Chinese and the "prudence" in English.

Firstly, "I" is added in many underlined parts. There are seven basic sentence patterns in English and the most fundamental element is SV. Namely, in English, a sentence requires a subject and a verb at least. Neither of them can be omitted; otherwise, it will be an ill-formed sentence and incomplete sentence. However, the integrity is not important in Chinese. It can also become a sentence without subject and is called a sentence without subject. For instance:

8) 没有调查就没有发言权。

He who makes no investigation and study has no right to speak.

Secondly, "it" and "them" are added in English while they are often omitted in Chinese. Compare the following:

9)Halliday put his pipe down, crossed his hands behind his neck, and turned his face towards the window.

韩礼德放下烟斗，两手交叉着放在脖子后面，转过头去看窗户。 
Thirdly, conjunctions including relative pronouns, relative adverbs, coordinating conjunctions, subordinating conjunctions and conjunctions representing the logic semantic relations of sentences are added. For instance:

10) 早知如此, 我就不来了。(It represents the conditional relation and “if” is omitted.)

If I had known it, I would not have come.

11) 明天要考试, 我不陪你去看电影了。(It represents the causal relation and "because” is omitted.)

I won't go to the movie with you, because we'll have an examination tomorrow.

12) 得了冠军你也不能骄傲。(It represents a concession relation and “even if” is omitted.)

Even if you win the championship, you should not be conceited.

We must pay high attention to the characteristics such as hypotaxis in English and parataxis in Chinese during translation and respect such characteristics to improve the readability. If not, a target language cannot even be readable. It is hoped that translators can be prudent in translation.

\section{Conclusion}

Clearly knowing the two major differences between English and Chinese, we can pay more attention to them in the course of learning and can consciously show the characteristics respectively in translation practices. Respecting them can help us to get rid of the influence and constraint of source language for the target language and a smooth, clear, natural and highly readable text can be translated accordingly. Meanwhile, there is another problem about the degree. For instance, overuse of nominalization in English is likely to result in the abstract and indistinct sentence meaning as well as the difficulty in comprehension. Therefore, to draw on advantages and avoid disadvantages, we need to respect the linguistic rules of English and Chinese respectively on the premise of naturalness and properness.

\section{References}

[1] Chen Wenbo. English-Chinese Translation Skills and Practices. Beijing: World Affairs Press, 1998.

[2] Gao Yuan. Comparative Analysis and Error Analysis. Beijing: Beihang University Press, 2002.

[3] Lv Shuxiang. 1982. Essentials of Chinese Grammar. Beijing: Commercial Press.

[4] Mao Guoan. A Practical Course in Contrastive Studies of English and Chinese. Chongqing: Chongqing University Press, 2004.

[5] Shang Quanrong and Shou Dengkun. Adjectives in English. Zhengzhou: Henan Education Press, 1987.

[6] Song Jingsheng. 2003. Comparison of Positions of Chinese and English Conjunctions in Sentences. Journal of East China Shipbuilding Institute (Social Science), 2003, 2

[7] Alexander L G. Longman English Grammar. London: Longman Group Ltd, 1988.

[8] Biber D, et al. Longman Grammar of Spoken and Written English. Beijing: Foreign Language Teaching and Researching Press, 2000.

[9] Daniel R W. A Comprehensive Rhetoric. Boston: Little, Brown and Company

[10]Halliday M A K \& Hasin R. Cohesion in English. Beijing : Foreign Language Teaching and Researching Press, 2001.

[11]Leech G. Principle of Pragmatics. Lodon: Longman Group Ltd, 1983.

[12]Quirk, et al. A Comprehensive Grammar of the English Language. London: Longman Group Ltd, 1985. 
[13]Swan M. Practical English Usage. Oxford: Oxford University Press, 1980. 